OPEN ACCESS

Edited by:

Jasmin Joshi,

University of Applied Sciences

Rapperswil, Switzerland

Reviewed by:

Ciska Veen

Netherlands Institute of Ecology (NIOO-KNAW), Netherlands

Anna O'Brien,

University of Toronto, Canada

*Correspondence: Kendall K. Beals kbeals2@vols.utk.edu Jessica A. M. Moore mooreja1@ornl.gov

Specialty section:

This article was submitted to Behavioral and Evolutionary Ecology,

a section of the journal

Frontiers in Ecology and Evolution

Received: 20 August 2019 Accepted: 28 May 2020

Published: 30 June 2020

Citation: Beals KK, Moore JAM, Kivlin SN,

Bayliss SLJ, Lumibao CY, Moorhead LC, Patel M, Summers JL, Ware IM, Bailey JK and Schweitzer JA (2020) Predicting Plant-Soil Feedback in the Field: Meta-Analysis Reveals

That Competition and Environmental Stress Differentially Influence PSF. Front. Ecol. Evol. 8:191. doi: 10.3389/fevo.2020.00191

\section{Predicting Plant-Soil Feedback in the Field: Meta-Analysis Reveals That Competition and Environmental Stress Differentially Influence PSF}

\author{
Kendall K. Beals ${ }^{1 *}$, Jessica A. M. Moore ${ }^{1,2 *}$, Stephanie N. Kivlin ${ }^{1}$, Shannon L. J. Bayliss ${ }^{1}$, \\ Candice Y. Lumibao ${ }^{1}$, Leigh C. Moorhead ${ }^{1,3}$, Megan Patel ${ }^{1,4}$, Jennifer L. Summers ${ }^{1}$, \\ Ian M. Ware ${ }^{1,5}$, Joseph K. Bailey ${ }^{1}$ and Jennifer A. Schweitzer ${ }^{1}$ \\ ${ }^{1}$ Department of Ecology and Evolutionary Biology, University of Tennessee, Knoxville, Knoxville, TN, United States, \\ ${ }^{2}$ Bioscience Division, Oak Ridge National Laboratory, Oak Ridge, TN, United States, ${ }^{3}$ Office of Research and Development, \\ National Center for Environmental Assessment, United States Environmental Protection Agency, Research Triangle Park, NC, \\ United States, ${ }^{4}$ Oak Ridge Institute for Science and Education, Oak Ridge, TN, United States, ${ }^{5}$ Institute of Pacific Islands \\ Forestry, USDA Forest Service, Hilo, HI, United States
}

Past research on plant-soil feedbacks (PSF), largely undertaken in highly controlled greenhouse conditions, has established that plant species differentially alter abiotic and biotic soil conditions that in turn affect growth of other conspecific and heterospecific individuals in that soil. Yet, whether feedbacks under controlled greenhouse conditions reflect feedbacks in natural environments where plants are exposed to a range of abiotic and biotic pressures is still unresolved. To address how environmental context affects PSF, we conducted a meta-analysis of previously published studies that examined plant growth responses to multiple forms of competition, stress, and disturbance across various PSF methodology. We asked the following questions: (1) Can competition, stress, and disturbance alter the direction and/or strength of PSF? (2) Do particular types of competition, stress, or disturbance affect the direction and/or strength of PSF more than others? and (3) Do methods of conducting PSF research (i.e., greenhouse vs. field experiments and whether the source of soil inoculum conditioning is from the field vs. greenhouse) affect plant growth responses to PSF or competition, stress, and disturbance, or their interactions? We discovered four patterns that may be predictive of what future PSF studies conducted under more realistic conditions might reveal. First, relatively little is known about how PSF responds to environmental stress and disturbance compared to plant-plant competition. Second, specific types of competition enhanced negative effects of soil microbes on plant growth, and specific environmental stressors enhanced positive effects of soil microbes on plant growth. Third, whether PSF experiments are conducted in the field or greenhouse can change plant growth responses. And, fourth, how the soil conditioning phase is conducted can change plant growth responses. With more detail than previously shown, these results confirm that environmental context writ large can change plant growth responses in PSF 
experiments. These data should aid theory and predictions for conservation and restoration applications by showing the relative importance of competition, stress, and disturbance in PSF studies over time. Lastly, these data demonstrate how variation in experimental methods can alter interpretation and conclusions of PSF studies.

Keywords: plant-soil feedback, competition, stress, disturbance, environmental variation

\section{INTRODUCTION}

The past 25 years of research on plant-soil feedback (PSF), largely under highly controlled conditions, has established that plant species differentially alter abiotic and biotic soil conditions that in turn affect growth of other conspecific and heterospecific individuals in that soil (Bever, 1994; Bever et al., 1997; Wardle et al., 2004; Ehrenfeld et al., 2005; Kulmatiski and Kardol, 2008; Mangan et al., 2010; Putten et al., 2013). The broad conclusion from this research is that positive and negative PSF can shape community composition and ecosystem functioning by driving patterns of plant diversity, succession, and invasion (Bever et al., 1997; Mills and Bever, 1998; Klironomos, 2002; Reynolds et al., 2003; Mangan et al., 2010; Johnson et al., 2012; Van Der Heijden et al., 2018). Yet most PSF experiments are rarely conducted under the environmental conditions where large-scale ecological and evolutionary mechanisms occur, that is, in the field. Various findings indicate differences in PSF between greenhouse and field experiments (Putten et al., 2016; Schittko et al., 2016; Florianová and Münzbergová, 2018; Heinze and Joshi, 2018; Kivlin et al., 2018; Forero et al., 2019) which suggest that inferences from greenhouse studies may not accurately represent how PSF functions on the landscape (Kulmatiski and Kardol, 2008; Putten et al., 2013, 2016; Smith-Ramesh and Reynolds, 2017; Crawford et al., 2019; De Long et al., 2019). While greenhouse experiments have the advantage of maintaining control over non-focal variables and are crucial for confirming and falsifying mechanisms, recent field based PSF research has demonstrated that thoughtful field study designs can generate tractable and interesting results (Long et al., 2019). By not accounting for the surrounding environmental matrix in which plant-soil interactions occur, it is difficult to accurately predict community composition and productivity based on the plant species that are either inhibited by negative PSF or those that persist by positive PSF.

Competition, stress, and disturbance are common environmental pressures that occur across the landscape. To cope with these pressures, plants can differentially allocate resources to growth, reproduction, or maintenance. Selection for each of these strategies depends on tradeoffs for traits that allow tolerance to competition, stress, or disturbance events. This phenomenon, known as the competition-stress-disturbance (C-S-D) hypothesis (Grime, 1977), predicts that competitive plants thrive in ecosystems with high competition because of evolved traits such as large size and extensive fine roots. Likewise, traits such as high stem and root storage of resources allow stresstolerant plants to thrive under highly stressful conditions, while disturbance-resilient plants thrive in frequently or intensely disturbed ecosystems due to evolved traits such as fast growth rates and fast reproduction. Changes in plant traits in response to these environmental pressures may subsequently impact plant-soil interactions by altering soil biota and chemistry. Although the C-S-D hypothesis is well-studied (Herms and Mattson, 1992; Reich, 2014; Rosado and de Mattos, 2017), it does not directly describe the role of plant-soil interactions in plant response to the biotic and abiotic environment (which C-S-D represents) that may enhance or impede a plant's ability to cope with competition, stress, or disturbance. For example, when accounting for soil microbial dynamics under well-watered vs. drought-stress conditions, a greenhouse study (Lau and Lennon, 2012) found that Brassica rapa fitness increased under drought when focal plants were grown with "dry-adapted" soil microorganisms. As such, examining PSF across environmental gradients of competition, stress, or disturbance will provide insight into plant-soil dynamics that influence plant species' persistence or decline under more realistic field conditions.

Competition is a prominent driver of plant fitness, community composition, and coexistence (Tilman, 1982; Callaway and Walker, 1997; Chesson, 2000; Aschehoug et al., 2016) and may influence the strength and direction of PSF in several ways. While competition reduces resource availability, a plant may benefit from its "home" microbiome and thus exhibit positive PSF if soil mutualists increase the availability of limiting resources (Bessler et al., 2012). Conversely, the phenomenon of reduced survival and density of conspecific seedlings near mature or parent conspecifics (Burkey, 1994; Bell et al., 2006; Mangan et al., 2010; Rolhauser et al., 2011; Reinhart et al., 2012; Comita et al., 2014) suggests that intraspecific competition may promote negative PSF due to accumulation of host-specific soil pathogens. The relative importance of competition and PSF on plant performance was examined in a recent meta-analysis (Lekberg et al., 2018). Distinguishing between both inter- vs. intraspecific and low vs. high-density competition and across multiple PSF treatments Lekberg et al. (2018) found antagonistic interactive effects of competition and PSF. In other words, the combined effect of competition and PSF was greater than the individual effects of PSF or competition alone, often leading to highly reduced plant growth and demonstrating how biotic interactions can alter PSF outcomes. Plant growth responses to PSF are likely also modified by plant responses to changes in the abiotic environment, although this was not tested by Lekberg et al. (2018).

As human-induced global change accelerates, stress (defined here as prolonged or continuous environmental pressures) and disturbance events defined here as sudden, temporally constrained changes in the environment) (Hillebrand and Kunze, 
2020) are predicted to rapidly increase (Allen et al., 2010; Dai, 2013; Barbero et al., 2015). These types of environmental pressures will likely have additionally profound effects on plant distributions and plant-soil interactions. Increasing evidence suggests that plant response to environmental stressors including drought (Lau and Lennon, 2012; Vílchez et al., 2016; Kannenberg and Phillips, 2017), herbivory (Badri et al., 2013), and salt tolerance (Qin et al., 2016) can be mediated in part by interactions with soil biota.

As with competition, environmental stress, or disturbance can alter resource availability (e.g., soil nutrients, light, water). Fertilization is often considered a benefit to plant growth, however there is evidence that it can cause an imbalance in PSF. A surplus of nutrients from nutrient deposition could promote positive PSF if plant defense against pathogens is enhanced with high resource availability (Smith-Ramesh and Reynolds, 2017). Positive PSF may also occur under low-resource stress if plants rely on host-specific soil microbes for limiting nutrients (Reynolds et al., 2003; Revillini et al., 2016). Alternatively, nutrient inputs in excess of plant growth demands can shift the balance of plant-microbe interactions and prompt dissociations between plants and their home soil biota (Wallenda and Kottke, 1998; Treseder and Allen, 2002; Revillini et al., 2016). Nutrient inputs from fertilizer applications can lead to limitation of other micronutrients (Whalen et al., 2018) and changes in soil chemistry (Erisman et al., 2013) that modify a plant's association with the soil microbiome. Negative PSF could also occur if soil pathogens thrive under resource-rich conditions (Hersh et al., 2012; Spear et al., 2015).

Other types of environmental stressors like aboveground herbivory could promote negative PSF if grazed plants are less able to defend from soil pathogens that are more abundant in conspecific-conditioned soil (Smith-Ramesh and Reynolds, 2017). Negative PSF under herbivory may also occur if grazed plants reduce carbon allocation to roots and thus reduce the ability to support host-specific microbial mutualists (SmithRamesh and Reynolds, 2017). Alternatively, positive PSF could occur if grazed plants allocate growth to roots and thus support host-specific microbial mutualists (Smith-Ramesh and Reynolds, 2017). Disturbance events such as fire could promote either negative or positive PSF depending on how soil microbes respond to fire disturbance. Fire has generally been found to decrease microbial biomass and diversity (Dooley and Treseder, 2012; Pressler et al., 2019; Whitman et al., 2019) due to heatsterilization of microbes and loss of soil carbon valuable for soil microbes (Dooley and Treseder, 2012). Negative PSF could occur if abundance of host-specific mutualists declines from fire, whereas positive PSF could occur if fire reduces soil pathogen abundance. However, it is possible that increases in ash deposition following fire could stimulate microbial growth by increasing availability of soil inorganic nitrogen and alleviating nutrient limitation (Rau et al., 2008; Schafer and Mack, 2010; Dooley and Treseder, 2012). In this scenario, negative or positive PSF could occur depending on whether host-specific mutualists or pathogens thrive from nutrient availability.

Predicting PSF accurately on the landscape also requires examining the methods under which plant growth response is measured and the methods that are used to condition the soil microbiome. PSFs have been found to vary between greenhouse and field experiments. An experiment by Schittko et al. (2016) for example, found that the majority of plant species in an experiment exhibited positive PSF under controlled greenhouse conditions, but did not exhibit any significant PSF under natural field conditions. A meta-analysis of the PSF literature seems to corroborate this observation-experiments conducted in the greenhouse often produce larger effect sizes in PSF than those conducted in the field (Kulmatiski et al., 2008; Forero et al., 2019). This broad pattern likely suggests that the true importance of PSF on the landscape is different than what is measured in greenhouse studies. Importantly, experiment location informs interpretation of the specific mechanisms of PSF. Field experiments testing PSF allow for understanding how a natural environment influences soil effects on plants, whereas PSF experiments conducted in the greenhouse do not provide this level of understanding (SmithRamesh and Reynolds, 2017).

Similarly, how the soil microbiome is conditioned can greatly influence plant growth. An important distinction between greenhouse-conditioned soil inoculum and field-conditioned soil inoculum is that greenhouse-conditioned soil contains primarily only microbes associated with the focal conditioning plant(s), whereas field-conditioned soil contains microbes associated with site-specific edaphic characteristics in addition to microbes associated with the focal conditioning plant(s). Subsequent differences in microbial composition can alter plant growth. For example, the perennial forb Centaurea maculosa exhibited negative PSF with field-conditioned soil inoculum and positive PSF with greenhouse-conditioned soil inoculum (Callaway et al., 2004). In this instance, greenhouse-conditioned soil could result in the accumulation of microbial symbionts or the loss of pathogens compared to field-conditioned soil (Kulmatiski et al., 2008). Similar to the role of experiment location, soil conditioning source can also inform interpretation of the specific mechanisms of PSF. Using soil conditioned by focal plants in the greenhouse limits understanding how the environmental context of a natural field environment influences plant effects on soil (Smith-Ramesh and Reynolds, 2017).

Several recent papers have specifically called for empirical studies that measure PSF under manipulations of abiotic and biotic variation (Putten et al., 2013, 2016; Smith-Ramesh and Reynolds, 2017; Lekberg et al., 2018; Crawford et al., 2019). However, no concerted effort has been made to assess the current extent and relative importance of PSF across environmental gradients of competition, stress, or disturbance. We expanded upon a recent effort (Lekberg et al., 2018) that analyzed the interaction between PSF and plant competition. Lekberg et al. found that PSF varied when plants were exposed to competitors or not. We build on that study by examining PSF when plants are exposed to environmental stress or disturbance, to leverage our understanding of plant C-S-D strategies in making predictions of PSF. We also investigated how PSF responses to C-S-D may vary in greenhouse and field conditions to further develop PSF predictive frameworks. Using data from 300 independent manipulations from 76 publications, we examined plant growth responses to multiple forms of competition, 
stress, and disturbance across a range of PSF methods to identify trends in plant-soil interactions across biotic and abiotic environments and experimental conditions. To understand the relative importance of environmental context as well as common methods for PSF, we addressed the following questions to better understand and predict what PSF outcomes might be expected under realistic field conditions: (1) Can competition, stress, and disturbance alter the direction and/or strength of PSF? (2) Do particular types of competition, stress, and disturbance affect the direction and/or strength of PSF more than others? (3) Do methods of conducting PSF research (i.e., greenhouse vs. field experiments and whether the source of soil conditioning inoculum is from the field vs. greenhouse) affect plant growth responses to PSF or competition, stress, and disturbance, or the interaction of both?

\section{METHODS}

\section{Paper Selection}

We collected previously published, peer-reviewed data of PSF in response to experimental manipulations of competition from studies used in a recent meta-analysis (Lekberg et al., 2018) supplemented with a search conducted in Web of Science for more recent competition studies as well as stress or disturbance. We searched through April 2019 for publications that crossed PSF experiments with one of the environmental manipulations of competition, stress, or disturbance using the following search terms "plant-soil feedback"” OR "PSF” AND "competi*”; "plantsoil feedback*" OR "PSF" AND “stress" OR "drought” OR "herbiv*” OR "precipitation" OR "temperature" OR "salinity" OR "light" OR "fertiliz"” OR "enrichment"; "plant-soil feedback*” OR "PSF” AND "disturbance" OR "mining” OR "mine tailings" OR “wind” OR "hurricane" OR "tornado" OR "fire” OR "grazing” OR "agriculture." We identified additional publications not found in our initial Web of Science search by searching for studies that had cited publications included in our initial data set. Several publications were included twice in our data set because they measured PSF under multiple manipulations of competition, stress, or disturbance (Larios and Suding, 2015; Shivega and Aldrich-Wolfe, 2017; Yu et al., 2017; Hawkins and Crawford, 2018; Zhao et al., 2018), or under more than one stress or disturbance level (Heinze et al., 2016; Valliere and Allen, 2016).

We screened publications for studies that included (1) soil treatment methods indicative of a manipulative PSF experimental design (as detailed below), (2) plant growth responses to soil treatments, specifically, either aboveground biomass or plant height, (3) factorial design of PSF treatments crossed with some manipulation of either competition, stress, or disturbance, where the experiments were undertaken in the field or in the greenhouse and (4) measures of mean, error, and sample size for plant growth in all treatments. We did not have any criteria for the length of the study. We excluded one publication (Brandt et al., 2015) and experiments from several publications (Coykendall and Houseman, 2014; Maron et al., 2016; Zuppinger-Dingley et al., 2016) from the Lekberg et al. (2018) data set because of the absence of a full factorial design. We found nine additional PSF $\mathrm{x}$ competition publications that were not included in the Lekberg et al. (2018) meta-analysis (de la Peña et al., 2010; Chen et al., 2012; Zhang et al., 2014; Chung and Rudgers, 2016; Bezemer et al., 2018; Hawkins and Crawford, 2018; Xue et al., 2018; Zhao et al., 2018; Lozano et al., 2019). Soil feedback manipulations for PSF experimental design were conducted in three ways in the included publications: (1) soil conditioned from the focal species ("home" soil) or from a heterospecific species ("away" soil) (hereafter, home-conditioned vs. away-conditioned), (2) live soil (majority of soil biota active; hereafter referred to as "active soil") or sterilized soil (majority of soil biota absent inactive; hereafter referred to as "inactive soil"), or (3) soil untreated or treated with fungicide (non-fungicide treated soil hereafter referred to as "diverse soil"). All studies that included treatments of untreated vs. fungicide soil or treatments of live vs. sterilized soil used soil that had been conditioned by plants. Publications that measured competition included one or two types of competition treatments, either the number of plants differed between treatments and the focal plant grew alone or with other plants (here referred to as "alone-together"). In other instances, competition was quantified as equal number of plants between treatments and the focal plant was exposed to either intra- or interspecific competition (here referred to as "interspecific-intraspecific"). The soil treatments were then added factorially, either directly as field-conditioned inocula (at various quantities and according to treatments) or as a second phase conditioned soil from a two-part design in which plants were initially grown in pots in a greenhouse conditioning phase using a field soil inoculum. Soil conditioned from the first phase was then used as the inoculum in the PSF phase of the experiment (see Kulmatiski et al., 2008 for details of these designs).

\section{Data Collection}

Mean values and measures of plant growth were collected from text and tables in the main publication and/or Supplemental Information. We used GraphClick (Arizona Software) to extract mean and standard error values from figures when raw data was not provided. If not provided, standard deviations were back calculated from standard errors and sample sizes $(\mathrm{SD}=\mathrm{SE} \times \sqrt{ } n)$. In cases where data was not clearly available in the publication, we contacted the authors. We excluded two publications (Medina-Roldán et al., 2012; Kaisermann et al., 2017) for which we received no response from authors, and therefore could not include these studies. Some studies measured the performance of multiple focal species, and thus included multiple experiments. Some studies contained multiple trials within an experiment in which a focal species was examined under multiple treatments (i.e., multiple home/away soils, multiple competitors, or multiple levels of stress or disturbance).

For each record in our dataset, we recorded the type of soil feedback manipulation (as described above) and environmental manipulation (competition manipulation described above). Stress manipulations consisted of drought, fertilization (as a representation of nutrient deposition), grazing/herbivory, shade (light availability), mining, and temperature. Disturbance manipulations consisted of fire and tornado. We differentiated stress manipulations as those that represented prolonged 
or continuous environmental pressures experienced by focal plant(s) and disturbance manipulations as those that represent sudden, temporally constrained changes in the environment (Hillebrand and Kunze, 2020).

We recorded duration of the feedback experiment and multiple descriptors of the focal plant. We also recorded the location of where the soil was collected, as well as the source of inoculum conditioning phase (i.e., collected directly from the field $=$ conditioned in the field, or collected from a training phase in pots under controlled conditions $=$ conditioned in the greenhouse). Field-conditioned soil represents microbiota associated with specific plant species in the field as well as microbiota associated with the edaphic conditions of that site (i.e., $\mathrm{pH}$, nutrient levels, soil moisture), whereas greenhouseconditioned soil represents mostly microbiota associated with the plants that were used to condition the inoculum. For each record we also recorded experiment location. Experiment location was defined as greenhouse if the plant growth response to soil phase was conducted in the greenhouse. Location was defined as field if the response phase was conducted in a natural field environment. Extracted data of all publications included in the dataset is available in the (Table S1).

\section{Effect Size Calculations}

We conducted an interaction meta-analysis to assess effects of PSF, competition, stress, and disturbance across PSF methods on plant growth using the relative interaction intensity (RII) as the effect size metric (Armas et al., 2004). We preferred this metric over the log response ratio - a widely used metric in ecological meta-analyses-because unlike the log response ratio, RII is bounded between -1 and 1 , and therefore symmetrical around zero, and it can be calculated if plant growth is zero in control groups. Following Armas et al. (2004), RII is calculated as:

$$
\frac{\text { treatment }- \text { control }}{\text { treatment }+ \text { control }}
$$

We therefore calculated the effect of PSF manipulation as:

$$
\frac{\bar{Y}_{c, f}-\bar{Y}_{c, n}}{\bar{Y}_{c, f}+\bar{Y}_{c, n}}
$$

And the effect of competition, stress, or disturbance (i.e., C-S-D) manipulation as:

$$
\frac{\bar{Y}_{t, n}-\bar{Y}_{c, n}}{\bar{Y}_{t, n}+\bar{Y}_{c, n}}
$$

To quantify the combined effect of PSF with C-S-D, we followed the calculation in Kivlin et al. (2013) modified from Armas et al. (2004) for a two-factor RII. The interactive effect of soil feedback and competition, stress, or disturbance can be described as the effect of PSF when competition, stress, or disturbance is present compared to the effect of PSF when competition, stress, or disturbance is absent. This was calculated as:

$$
\frac{\bar{Y}_{t, f}-\bar{Y}_{t, n}}{\bar{Y}_{t, f}+\bar{Y}_{t, n}}-\frac{\bar{Y}_{c, f}-\bar{Y}_{c, n}}{\bar{Y}_{c, f}+\bar{Y}_{c, n}}
$$

In these equations, $\bar{Y}$ is the mean plant growth for $t=$ treatment or $c=$ control for the competition, or stress, or disturbance treatment, and $f=$ soil feedback imposed (away-conditioned soil, live soil, or non-fungicide treated soil) or $n=$ no soil feedback imposed (home-conditioned soil, sterilized soil, or fungicidetreated soil). To calculate the $95 \%$ confidence intervals around the means for each record, variance was weighted by the sample size $(n)$ and calculated using the standard deviation $(s)$. For each record, we followed the calculations used in Kivlin et al. (2013) to calculate variance. Variance for the main effect of PSF was calculated as:

$$
P S F V i=\frac{s_{c, f}^{2}}{n_{c, f} \bar{Y}_{c, f}^{2}}+\frac{s_{c, n}^{2}}{n_{c, n} \bar{Y}_{c, n}^{2}}
$$

and the variance of the main effect of competition, stress or disturbance as:

$$
C-S-D V i=\frac{s_{t, n}^{2}}{n_{t, n} \bar{Y}_{t, n}^{2}}+\frac{s_{c, n}^{2}}{n_{c, n} \bar{Y}_{c, n}^{2}},
$$

Variance for the interaction of PSF and competition, stress or disturbance was calculated as:

$$
\text { Int Vi }=\frac{s_{c, n}^{2}}{n_{c, n} \bar{Y}_{c, n}^{2}}+\frac{s_{t, n}^{2}}{n_{t, n} \bar{Y}_{t, n}^{2}}+\frac{s_{c, f}^{2}}{n_{c, f} \bar{Y}_{c, f}^{2}}+\frac{s_{t, f}^{2}}{n_{t, f} \bar{Y}_{t, f}^{2}}
$$

An RIIPSF significantly greater than zero indicates that awayconditioned, active, or diverse soil enhances plant growth. An RIIPSF significantly less than zero indicates that awayconditioned, active, or diverse soil inhibits plant growth. A RIIPSF not significantly different from zero indicates that away-conditioned, active, or diverse soil does not alter plant growth. An RII $\mathrm{CSD}$ significantly greater than zero indicates plant growth is enhanced by competition, stress, or disturbance, whereas an $\mathrm{RII}_{\mathrm{CSD}}$ significantly less than zero indicates plant growth is inhibited by competition, stress, or disturbance. An RII $_{C S D}$ not significantly different from zero indicates that competition, stress, or disturbance does not alter plant growth. An $\mathrm{RII}_{\text {Int }}$ significantly greater than zero indicates a synergistic effect such that away-conditioned, active, or diverse soil enhances plant growth under competition, stress, or disturbance. An RII Int significantly less than zero indicates an antagonistic effect such that away-conditioned, active, or diverse soil inhibits plant growth under competition, stress, or disturbance. An $\mathrm{RII}_{\text {Int }}$ not significantly different from zero indicates that the interactive effects of PSF and competition, stress, or disturbance are neutral. Specifically, a neutral 
$\mathrm{RII}_{\text {Int }}$ indicates that away-conditioned, active, or diverse soil does not influence plant growth under competition, stress, or disturbance.

\section{Data Analysis}

We used the rma.mv function in the metafor package (Viechtbauer, 2010) in R 3.5.2 for all analyses. In all analyses, we separated the dataset by competition studies, stress studies, and disturbance studies and thus ran competition, stress, and disturbance models separately. Prior to analyses to assess our questions, we first identified the individual effects of PSF and C-S-D by building separate multivariate mixed effects models using $R I I_{P S F}$ and $R I I_{C S D}$ as response variables and PSF Vi and CSD Vi as the variance. These models tested for the main effects of PSF and C-S-D averaged across soil feedback manipulations and across competition, stress, disturbance manipulations. Thus, we tested for differences in plant growth in response to types of soil feedback and types of competition, stress, disturbance by including soil manipulation and C-S-D manipulation as moderators in separate models. A moderator in the rma.mv function is analogous to a fixed effect in an ANOVA model (Viechtbauer, 2010) and allows the model to calculate the effect size of specific levels of a factor.

To address the first question of whether competition, stress, and/or disturbance alters the direction and/or strength of PSF, we built multivariate mixed effects models using $R I I_{\text {Int }}$ as the response variable and as Int $V i$ as the variance to identify the main interactive effect of PSF $x$ C-S-D (averaged across soil feedback manipulations and across competition, stress, disturbance manipulations). To address the second question of whether particular types of competition, stress, and disturbance affect the direction and/or strength of PSF more than others, we built separate multivariate mixed effects $R I I_{\text {Int }}$ models that included C-S-D manipulation as a moderator. To address the third question of whether methods of conducting PSF research alter the individual effects of PSF, or C-S-D, or the interactive effect of PSF x C-S-D, we built additional $R I I_{\text {Int }}$ mixed effects models using experiment location (field vs. greenhouse) and soil inoculum conditioning source (field-conditioned vs. greenhouseconditioned) as moderators.

We included plant species as a random effect in all models because species are not independent and past evolutionary history may affect plant response regardless of treatment (Wooliver et al., 2017). Including plant species as a random effect also allows us to make comparisons across studies. To further account for phylogenetic variation of plant growth responses, we replicated the analysis using plant family as a random effect. Results did not vary between the species and family analyses. While it is likely that the strength of PSF varies with plant ontogeny (Kardol et al., 2013), the included studies lacked sufficient replication in experiment duration to use duration as another random effect. For all models we performed post-hoc tests using the linearHypothesis function in the car package (Fox et al., 2013) to test whether effect sizes differed from one another. We report QM as the test statistic for moderator coefficients of the rma.mv models. We considered results to be significantly different from zero if $\alpha \leq 0.05$.

\section{RESULTS}

\section{Distribution of Studies}

Using the selection criteria, we identified 300 studies from 76 publications that measured plant growth in response to different soil PSF methods in a specific environmental context (competition, stress, or disturbance). Of these, 199 studies (43 publications) measured PSF with competition, 95 studies measured PSF with stress (34 publications), and 5 studies measured PSF with disturbance ( 2 publications). The majority of studies were conducted in the greenhouse and $86 \%$ of all studies used grasses or forbs as the focal plant species. Field experiments comprised only $9 \%$ of all studies (29 studies from 7 publications); 26 field studies focused on competition (6 publications), and 3 field studies focused on stress (1 publication).

\section{Main Effects of PSF, Competition, Stress, and Disturbance on Plant Growth}

In general, plant growth responses to the main effects of PSF, stress, and disturbance were neutral and the response to competition was negative (Figure 1A). PSF had a generally neutral effect on plant growth (Figure 1A; $p=0.28$; Table S2, row $3)$. However, the direction of PSF varied by type of soil feedback manipulation (Figure 2A; QM $=28.43, p<0.0001$; Table S2, rows 5-7). Active (i.e., live) soil reduced plant growth compared to sterile soil ( $p<0.0001$; Table S2, row 6), and the effect of PSF was neutral in studies that tested home vs. away-conditioned soil ( $p=0.28$; Table S2, row 7) or in those that tested diverse vs. nondiverse soil (i.e., untreated vs. fungicide treated soil) $(p=0.97$; Table S2, row 5). Post-hoc analysis revealed that plant growth was reduced more in live vs. sterile soil manipulations than in home vs. away soil manipulations $\left(\chi^{2}=26.84, p<0.0001\right.$; Table S2, row 92) or untreated vs. fungicide manipulations $\left(\chi^{2}=3.97, p\right.$ $=0.05$; Table S2, row 90). PSF was similarly neutral in studies that tested home vs. away soil manipulations and untreated vs. fungicide manipulations $\left(\chi^{2}=0.20, p=0.66\right.$; Table S2, row 91).

Plant growth responses to competition, stress, and disturbance were variable and depended on the type of competition, stress, or disturbance imposed. Competition in general significantly reduced plant growth (Figure 1A; $p<0.0001$; Table S2, row 32 ), and the effect of plants grown together with a competitor was nearly $150 \%$ greater than the effect of inter- vs. intraspecific competition on plant growth (Figure 2A; $\chi^{2}=51.78, p<0.0001$; Table S2, row 113). Generally, stress had marginally negative effects on plant growth (Figure 1A; $p=0.22$; Table S2, row 56 ), and plant growth varied among different types of stress manipulations $(\mathrm{QM}=94.94, p<0.0001$; Table S2, rows 5863). As expected, drought (Figure 2A; $p=0.0001$; Table S2 row 58) and shade (Figure 2A; $p<0.0001$; Table S2, row 61) greatly reduced plant growth, and plant growth was reduced similarly under drought and shade $\left(\chi^{2}=2.66, p=0.20\right.$; Table S2, row 132). Fertilization, on the other hand, increased plant growth (Figure 2A; $p=0.0003$; Table S2, row 59). Increases in plant growth in response to fertilization were significantly different than reductions in plant growth in response to drought $\left(\chi^{2}=\right.$ 29.65, $p<0.0001$; Table S2, row 130) and shade $\left(\chi^{2}=70.51\right.$, $p<0.0001$; Table S2, row 137). Disturbance in general had no 




FIGURE 1 | (A) Main effects of PSF, competition, stress, and disturbance and (B) interaction effects of PSF x competition, PSF $x$ stress, and PSF x disturbance on plant growth. Competition main effects are averaged across alone/together and interspecific/intraspecific competition manipulations. Stress main effects are averaged across all stress manipulations (drought, fertilization, grazing/herbivory, mining, shade, temperature). Disturbance main effects are averaged across fire and tornado disturbance manipulations. PSF main effects are averaged across all soil manipulations (i.e., live/sterile, away/home, untreated/fungicide). Error bars represent lower and upper bounds of the confidence intervals. Asterisks indicate effect sizes significantly different from zero.

effect on plant growth (Figure 1A; $p=0.94$; Table S2, row 85). Disturbance caused by fire or tornado did not significantly affect plant growth ( $p>0.05$ for both; Table S2, rows 87-88) and plants responded similarly to these two disturbances $\left(\chi^{2}=1.86, p=\right.$ 0.17; Table S2, row 164).

\section{Do Competition, Stress, and/or Disturbance Alter the Direction of PSF?}

The strength of PSF was modified by plant-plant competition and environmental stress, but not disturbance. There was no general trend of competition affecting the outcome of PSF (Figure 1B; $p=0.21$; Table S2, row 166), but specific types of competition interacted with specific soil feedback manipulations differently $(\mathrm{QM}=8.22, p=0.22$; Table S2, rows 174-179). Interspecific competition reduced plant growth compared to intraspecific competition to a greater degree when plants were grown in away-conditioned soil ( $p=0.04$; Table S2, row 179). Interspecific competition affected plant growth similarly relative to intraspecific competition when plants were grown in active soils ( $p=0.42$; Table S2, row 178). Interspecific competition also affected plant growth similarly relative to intraspecific competition when plants were grown in diverse soils $(p=0.96$; Table S2, row 177). Post-hoc analysis showed that interspecific competition effects in away-conditioned soil were marginally different than active soil $\left(\chi^{2}=3.62, p=0.06\right.$; Table 2 , row 234) and similar to diverse soils $\left(\chi^{2}=0.43, p=0.51\right.$; Table S2, row 233). The effect of away-conditioned ( $p=0.82$; Table $\mathbf{S 2}$, row 176), active ( $p=0.25$; Table S2, row 175), and diverse soils ( $p$ $=0.36$; Table S2, row 174) was similar when plants were grown together with a competitor compared to growing alone.

There was a general synergistic effect of PSF and environmental stress (Figure 1B; $p=0.03$; Table S2, row 193), yet this trend was driven by the effect of drought stress which enhanced the effect of PSF (Figure 2B; QM $=19.06, p$ $=0.0002$; Table S2, row 195). All other stressors had no effect on plant growth when in combination with PSF: fertilization
(Figure 2B; $p=0.12$; Table S2, row 196), grazing/herbivory (Figure 2B; $p=0.18$; Table S2, row 197), shade (Figure 2B; $p=0.63$; Table S2, row 198), mining (Figure 2B; $p=0.34$; Table S2, row 199), and temperature (Figure 2B; $p=0.98$; Table S2, row 200). Post-hoc analysis showed that the effect of drought on PSF was significantly greater than fertilization $\left(\chi^{2}=8.50, p=0.004\right.$; Table S2, row 252), shade $\left(\chi^{2}=10.01\right.$, $p=0.001$; Table S2, row 254), and temperature stress $\left(\chi^{2}=\right.$ 4.60, $p=0.03$; Table S2, row 256). Drought effects on PSF were similar to grazing/herbivory $\left(\chi^{2}=2.62, p=0.11\right.$; Table S2, row 253) and mining $\chi^{2}=0.07, p=0.79$; Table S2, row 255), which were also positive but not statistically significant. All other environmental stressors had similar neutral effects on PSF ( $p$ $>0.05$ for all other post-hoc comparisons). We were unable to analyze effects of different environmental stressors on different PSF soil manipulations due to lack of sufficient studies. There was no general effect of PSF with environmental disturbance (Figure 1B; $p=0.80$; Table S2, row 217), and there were no disturbance-specific differences $(\mathrm{QM}=0.45, p=0.80$; Table S2, rows 219-220). Plant-soils feedbacks were not modified by fire (Figure 2B; $p=0.61$; Table S2, row 219) or tornados (Figure 2B; $p=0.66$; Table S2, row 220). These disturbances had similar neutral effects on PSFs $\left(\chi^{2}=0.40, p=0.53\right.$; Table S2, row 278). Disturbance effects on different PSF soil manipulations could not be further differentiated due to the low number of studies.

\section{Do the Effects of PSF and C-S-D Vary Between Methods Used to Conduct PSF Research?}

Whether the experiment was conducted in the field or greenhouse altered the effects of competition and stress on plant growth, but not the effect of PSF (Figure 3A). There was no difference in the effects of away-conditioned vs. homeconditioned soils $\left(\chi^{2}=0.24, p=0.62\right.$; Table S2, row 103) or diverse vs. non-diverse soils $\left(\chi^{2}=2.61, p=0.11\right.$; Table S2, row 105) on plant growth between studies where the feedback 

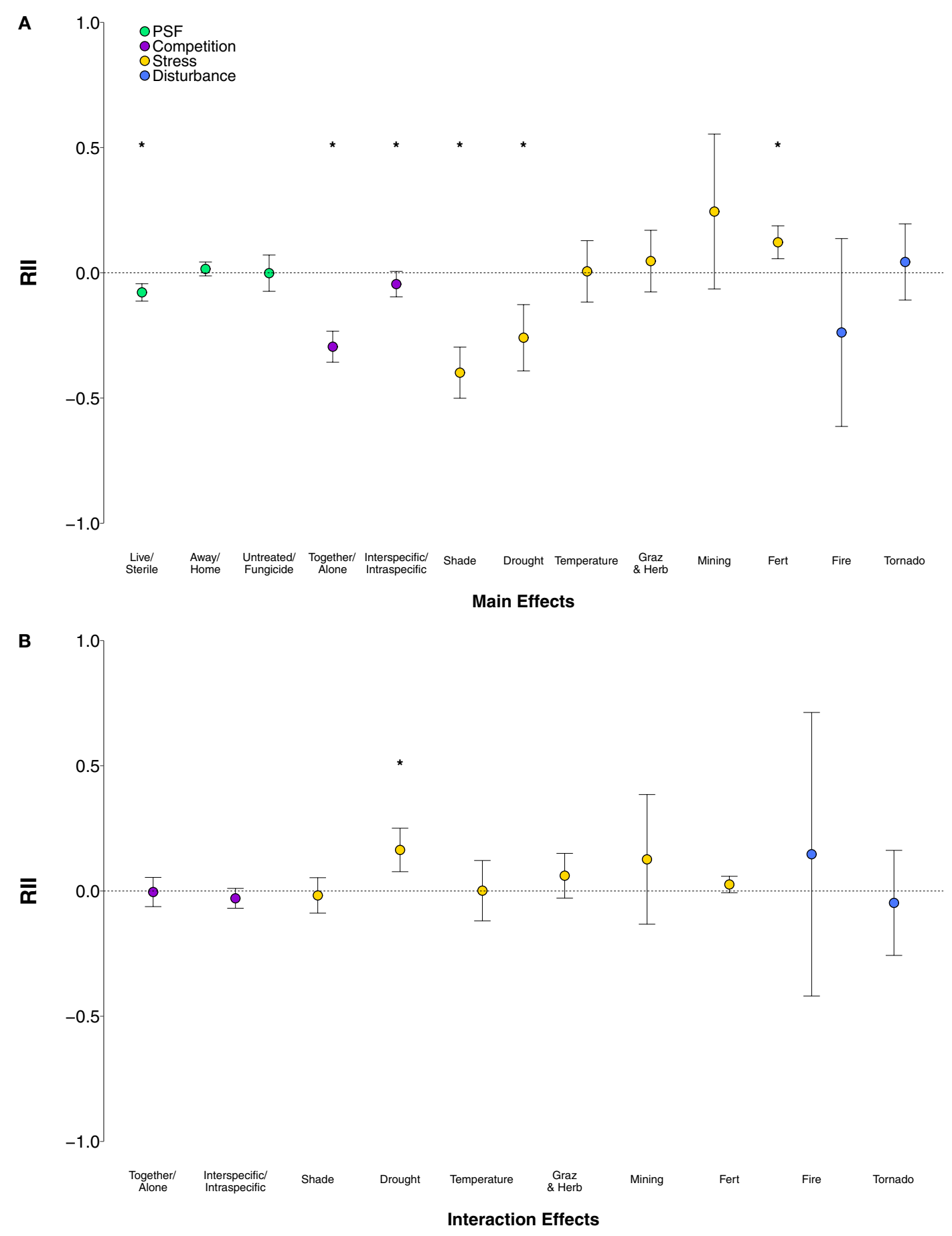

FIGURE 2 | (A) Main effects of PSF, competition, stress, and disturbance manipulations and (B) interaction effects of PSF x competition, PSF x stress, and PSF x disturbance manipulations on plant growth, averaged across soil manipulations (live/sterile, away/home, untreated/fungicide). Error bars represent lower and upper bounds of the confidence intervals. Asterisks indicate effect sizes significantly different from zero.

phase occurred in the field or greenhouse. Studies that used live and sterile soils as the soil feedback manipulation were only conducted in the greenhouse. Conversely, competition reduced plant growth when plants were grown in the field (Figure 3A; $p<0.001$; Table S2, row 42) and the greenhouse (Figure 3A; $p<0.001$; Table S2, row 43), but the effect was $138 \%$ stronger in field experiments than greenhouse experiments $\left(\chi^{2}=48.21\right.$, $p<0.001$; Table S2, row 122). This trend was driven by 


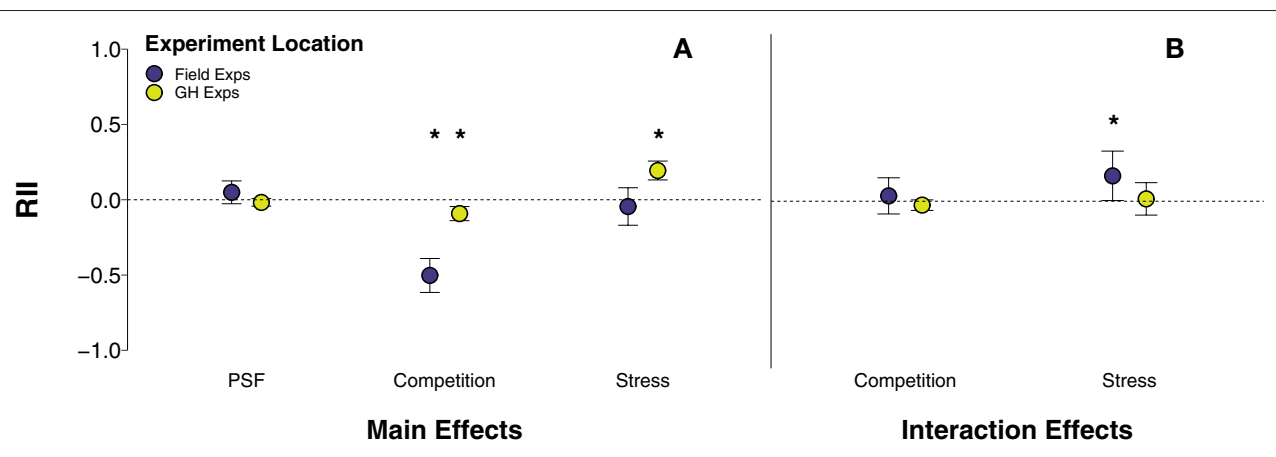

FIGURE 3 | (A) Main effects of PSF, competition, stress, and disturbance and (B) interaction effects of PSF x competition and PSF x stress between field and greenhouse experiments. Interaction effects of PSF $x$ competition and PSF x stress are averaged across soil manipulations (live/sterile, away/home,

untreated/fungicide) and across competition and stress manipulations. Error bars represent lower and upper bounds of the confidence intervals. Asterisks indicate

effect sizes significantly different from zero.

alone/together competition studies because inter/intra-specific competition studies were only conducted in the greenhouse. Only grazing/herbivory stress was conducted in both greenhouse and field settings, and thus it was the only stressor we could analyze between experiment location. Grazing/herbivory stress enhanced plant growth in the greenhouse (Figure 3A; $p<0.001$; Table S2, row 71), whereas its effects on plant growth were neutral in field experiments (Figure 3A; $p=0.48$; Table S2, row 70). Grazing/herbivory stress enhanced plant growth over $300 \%$ more in greenhouse experiments than in field experiments (Figure 3A; $\chi^{2}=11.31, p<0.001$; Table S2, row 157). Disturbance studies were only tested in greenhouse conditions.

The interactions between PSF and competition were neutral in both field and greenhouse experiments (Figure 3B; QM $=2.52, p=0.28$; Table S2, rows 181-182) and post-hoc analysis showed that these effects were similar between field and greenhouse experiments $\left(\chi^{2}=0.95, p=0.33\right.$; Table S2, row 245). Contrary to the finding that the main effect of grazing/herbivory was only positive in greenhouse experiments, there was a synergistic effect of PSF and grazing/herbivory only in field experiments (Figure 3B; $p=0.04$; Table S2, row 202). In other words, away-conditioned, active or diverse soil enhanced plant growth under grazing/herbivory in field experiments. However, post-hoc analysis showed that the interaction of PSF and grazing/herbivory in field experiments was not significantly different than the neutral effect of PSF and grazing/herbivory in greenhouse experiments $\left(\chi^{2}=2.34, p=0.13\right.$; Table S2, row 268). Disturbance interactions with PSFs were only tested in greenhouse conditions.

In general, soil inoculum conditioning source modified the effect of PSF on plant growth (Figure 4A; QM $=34.93, p$ $<$ 0.0001; Table S2, rows 23-24). Away-conditioned, active, or diverse soil reduced plant growth when soil inoculum was conditioned in the field (Figure 4A; $p<0.0001$; Table S2, row 23) and enhanced plant growth when soil inoculum was conditioned in the greenhouse (Figure 4A; $p=0.007$; Table S2, row 24). The various soil feedback manipulations also responded differently depending on the source of the conditioning phase. Active soil reduced plant growth when conditioned in the field $(p=0.03$;
Table S2, row 26) but had no effect on plant growth when conditioned in the greenhouse ( $p=0.40$; Table S2, row 27). The effects of away-conditioned soil on plant growth did not vary between field-conditioned ( $p=0.20$; Table S2, row 29) or greenhouse-conditioned soil ( $p=0.50$; Table S2, row 30$)$.

The interaction of PSF and competition was similarly neutral between experiments that used field-conditioned and greenhouse-conditioned inoculum (Figure 4B; $\chi^{2}=0.04, p=$ 0.84; Table S2, row 247). In general, the interaction of PSF and environmental stress was slightly synergistic when soil inoculum was conditioned in the field (Figure 4B; QM $=4.92, p=0.08$; Table S2, row 205). This trend was likely driven by drought, fertilization, and grazing/herbivory studies in which the average effects of PSF and each of these stressors was positive, though not statistically significant. However, post-hoc analysis showed that the interaction of PSF and stress with field-conditioned soil inoculum was not significantly different than the neutral effect of PSF and stress with greenhouse-conditioned soil inoculum $\left(\chi^{2}\right.$ $=0.52, p=0.47$; Table S2, row 270). Conversely, the interaction of PSF and mining stress was slightly synergistic when soil was conditioned in the greenhouse ( $\mathrm{QM}=4.73, p=0.09$; Table S2, row 215). Away-conditioned, active, or diverse soil enhanced plant growth $300 \%$ more under mining stress when soil inoculum was conditioned in the greenhouse rather than conditioned in the field ( $\chi^{2}=3.81, p=0.05$; Table S2, row 276). Studies that manipulated temperature were not included in this analysis as these studies only included greenhouse-conditioned soil.

\section{DISCUSSION}

In general, our meta-analysis revealed important patterns that may aid predictions of PSF under natural or field conditions where plant-plant competition and environmental stressors are common. The results of this meta-analysis suggest that soil microbes may generally reduce plant growth where plant-plant competition for resources occurs and may enhance plant growth under drought stress conditions. These results also highlight an important research gap in examining PSF under environmental disturbance. Additionally, this meta-analysis suggests that where 


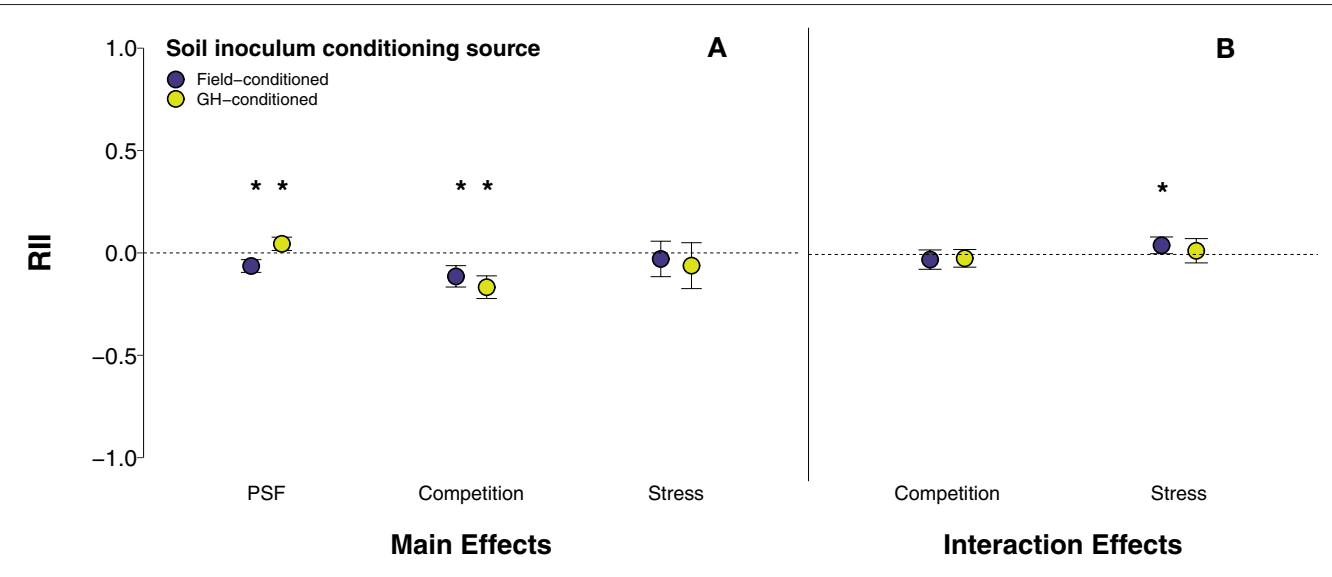

FIGURE 4 | (A) Main effects of PSF, competition, stress, and disturbance and (B) interaction effects of PSF x competition and PSF x stress between field-conditioned and greenhouse-conditioned soil inoculum. Interaction effects of PSF x competition and PSF x stress are averaged across soil manipulations (live/sterile, away/home, untreated/fungicide) and across competition and stress manipulations. Error bars represent lower and upper bounds of the confidence intervals. Asterisks indicate effect sizes significantly different from zero.

PSF experiments are conducted (field or greenhouse) affects the outcome of the study-especially when plants are competing. The nature of the soil conditioning manipulation (live vs. sterile, home vs. away, or fungicide application) can change plant growth responses, and again this is most evident when plants are competing for limiting resources. Our meta-analysis corroborates and expands upon Lekberg et al. (2018) to confirm that environmental context writ large can alter plant growth responses in PSF experiments, at least in grass and forb species with which the majority of PSF studies have been conducted.

\section{Plant Competition, and Specific Environmental Stressors and Alter Direction and Magnitude of PSF}

Competition shapes resource availability (Tilman, 1982, 1990) which can subsequently affect PSF, and the data to date show that PSF is often more examined in response to plant-plant competition than to environmental stress and disturbance. While growing next to a plant compared to growing alone more greatly reduced plant growth than when plants were growing with conspecifics or heterospecifics, types of competition reduced plant growth differently depending on the type of soil feedback imposed. When focal plants were grown in awayconditioned soil, interspecific competition reduced plant growth more than intraspecific competition. This likely indicates that interspecific competition either enhanced negative effects of nonhost associated soil biota on plant growth or reduced beneficial effects of non-host associated soil biota on plant growth. When focal plants were grown in active or diverse soil, interspecific competition reduced plant growth to a similar degree to that of intraspecific competition. This could suggest that taxonomic composition of the soil microbiome is more important than microbial diversity for reducing plant growth under interspecific competition. Conversely, in alone vs. together competition studies, the effect of away-conditioned, active, and diverse soil was similar. This may suggest that just the presence of a soil microbiome is influential for inhibiting plant growth when a plant is in close proximity to a competitor.

While the frequency of environmental stress and disturbance are increasingly occurring in terrestrial landscapes, these data from 76 publications suggest that stress and disturbance can have both negative and positive effects on plant growth individually (e.g., drought and shade reduce growth but fertilization increases growth) but when combined with PSF, lead to few synergistic or antagonistic effects. While the combined effect of PSF and environmental stress was generally synergistic, the trend was driven by drought stress studies. Away-conditioned, active, or diverse soil enhanced plant growth under drought conditions. Though the exact mechanisms to explain this trend remain unclear, soil microbes may facilitate plant growth under lowresource stress if plants rely on microbes for acquiring limiting nutrients (Reynolds et al., 2003; Revillini et al., 2016). Although this meta-analysis found that the combined effect of PSF and grazing/herbivory was on average synergistic but not statistically significant, grazing/herbivory could potentially induce benefits of the soil microbiome to plant growth if plants allocated resources to roots and subsequently supported microbial mutualists (Smith-Ramesh and Reynolds, 2017).

This meta-analysis found that the combined effects of PSF and environmental disturbance were neutral for both fire and tornado disturbance treatments. It is unclear, however, whether this is a true pattern across fire and tornado disturbance or across many types of environmental disturbance because this dataset only includes five studies from two publications (Nagendra and Peterson, 2016; Senior et al., 2018). Soil microbiomes and their interactions with plants are likely to be affected by drastic landscape changes brought about by environmental stress and disturbance, yet this meta-analysis shows that there is not yet enough data to predict how PSF responds to environmentally disruptive events. This gap of knowledge highlights the necessity of PSF experiments to incorporate manipulations that are 
representative of environmental variation under global climate change (Putten et al., 2016; Long et al., 2019).

\section{Experiment Location and Soil Conditioning Source Affect the Outcomes of PSF Research}

Comparisons of field vs. greenhouse studies showed that PSF did not vary by experiment location. Competition had a more negative effect when experiments were conducted in the field rather than in the greenhouse. However, the combined effects of PSF and competition were similarly neutral between field and greenhouse experiments. Grazing/herbivory only increased plant growth in greenhouse conditions. The combined effect of PSF and grazing/herbivory was synergistic in field conditions and neutral in greenhouse conditions, though further analyses indicated that the interactive effects of PSF and grazing/herbivory were not significantly different between field and greenhouse experiments.

It is important to note that only $9 \%$ of these studies were conducted in the field, suggesting that we have little inference for the strength or direction that environmental variation will demonstrate when interacting with PSF to affect plant growth. The few interactive effects shown here both support and contradict studies showing that PSF can differ between greenhouse and field experiments in different environments (Putten et al., 2016; Schittko et al., 2016; Florianová and Münzbergová, 2018; Heinze and Joshi, 2018; Kivlin et al., 2018) demonstrating how little is understood about the function of PSF in nature (Forero et al., 2019).

PSF varied by soil inoculum conditioning source. Awayconditioned, active, or diverse soil reduced plant growth if soil was conditioned in the field and enhanced plant growth if soil was conditioned in the greenhouse. The combined effect of PSF and competition was similarly neutral between studies that used field-conditioned and greenhouse-conditioned soil inoculum. The combined effect of PSF and stress was slightly synergistic when soil inoculum was conditioned in the field, though this was not significantly different than the neutral effect of PSF and stress with greenhouse-conditioned soil inoculum. The combined effect of PSF and mining stress was slightly synergistic when soil was conditioned in the greenhouse. Awayconditioned, active, or diverse soil enhanced plant growth $300 \%$ more under mining stress when soil inoculum was conditioned in the greenhouse rather than in the field. While it is difficult to identify detailed mechanisms, the trend from this metaanalysis of increased plant growth in greenhouse-conditioned soil relative to field-conditioned soil may be due to lower microbial diversity in greenhouse-conditioned soil. Specifically, greenhouse-conditioned soil may contain lower abundance of pathogens than field-conditioned soil (Callaway et al., 2004; Kulmatiski et al., 2008).

These results demonstrate that there are multiple methodological approaches that both allow us to infer how field studies may respond and to show how variation in methods can change interpretation of results. The finding that effects of PSF can differ between greenhouse and field experiments provides justification for pairing PSF experiments in the greenhouse with those conducted in the field, when possible (Smith-Ramesh and Reynolds, 2017). Additionally, that the source of inoculum for PSF experiments can also mediate interactive effects show that careful interpretation is required of studies that use each method (Smith-Ramesh and Reynolds, 2017). Studies that use field-conditioned inoculum for example, should be mindful to infer that focal plants are responding to microbes associated with the focal conditioning plant(s) in addition to microbes associated with site-specific soil characteristics. Focal plants in studies that use greenhouse-conditioned inoculum, on the other hand, are responding primarily to microbes associated with the focal conditioning plant(s). Moreover, it should be noted that $86 \%$ of the focal plants examined in this meta-analysis are grasses and forbs. While, overall, we did not see mean differences in effect sizes among plant functional groups (data not shown-see results in Table S2), this result is related to by the reduced power to detect an effect due to low sample sizes of trees and shrubs that have been studied to date.

An important distinction between greenhouse-conditioned soil inoculum and field-conditioned soil inoculum is that greenhouse-conditioned soil contains primarily only microbes associated with the focal conditioning plant(s), whereas fieldconditioned soil contains microbes associated with site-specific edaphic characteristics in addition to microbes associated with the focal conditioning plant(s).

\section{CONCLUSIONS}

Environmental context writ large can change plant growth responses in PSF experiments, a conclusion supported by our analyses comparing the interactive effects of PSF with a range of competition, stress and disturbance types relative to their individual effects. Our results have direct application in ecological conservation and restoration because we show that positive PSF is synergistically enhanced by drought and stress. Additionally, our study suggests that field experiments may yield different responses than greenhouse experiments. Data from these 76 studies show the need for more research on PSF across environmental stresses and disturbances (i.e., two-thirds of these studies were conducted on competition) and the need for increased representation of a wide diversity of focal plant species, because the majority of PSF studies were conducted with grasses and forbs. The lack of studies investigating true gradients of stress and disturbance (i.e., multiple experimental levels, rather than presence-absence of different types of stress or disturbance) indicate that we know very little about how PSF effects will respond to stress and disturbance on the landscape. Our metaanalysis enables future research into plant community dynamics in a changing world. There is, therefore, much empirical work to look forward to.

\section{DATA AVAILABILITY STATEMENT}

All datasets generated for this study are included in the article/Supplementary Material. 


\section{AUTHOR'S NOTE}

This manuscript has been authored in part by UT-Battelle, LLC, under contract DE-AC05-00OR22725 with the US Department of Energy (DOE). The US government and the publisher, by accepting the article for publication, acknowledges that the US government retains a non-exclusive, paid-up, irrevocable, worldwide license to publish or reproduce the published form of this manuscript, or allow others to do so, for US government purposes. DOE will provide public access to these results of federally sponsored research in accordance with the DOE Public Access Plan (http://energy.gov/downloads/doe-publicaccess-plan).

\section{AUTHOR CONTRIBUTIONS}

KB, JM, SB, CL, LM, MP, JLS, and IW screened all potential papers and coded data for papers that were included in the meta-analysis, curated by $\mathrm{KB}$ and JM. KB and JM ran all initial

\section{REFERENCES}

Allen, C. D., Macalady, A. K., Chenchouni, H., Bachelet, D., Mcdowell, N., Vennetier, M., et al. (2010). A global overview of drought and heat-induced tree mortality reveals emerging climate change risks for forests. For. Ecol. Manag. 259, 660-684. doi: 10.1016/j.foreco.2009.09.001

Armas, C., Ordiales, R., and Pugnaire, F. I. (2004). Measuring plant interactions: a new comparative index. Ecology 85, 2682-2686. doi: 10.1890/03-0650

Aschehoug, E. T., Brooker, R., Atwater, D. Z., Maron, J. L., and Callaway, R. M. (2016). The mechanisms and consequences of interspecific competition among plants. Annu. Rev. Ecol. Evol. Syst. 47, 263-281. doi: 10.1146/annurev-ecolsys-121415-032123

Badri, D. V., Zolla, G., Bakker, M. G., Manter, D. K., and Vivanco, J. M. (2013). Potential impact of soil microbiomes on the leaf metabolome and on herbivore feeding behavior. New Phytol. 198, 264-273. doi: 10.1111/nph.12124

Barbero, R., Abatzoglou, J. T., Larkin, N. K., Kolden, C. A., and Stocks, B. (2015). Climate change presents increased potential for very large fires in the contiguous United States. Int. J. Wildland Fire 24, 892-899. doi: 10.1071/WF15083

Bell, T., Freckleton, R. P., and Lewis, O. T. (2006). Plant pathogens drive density-dependent seedling mortality in a tropical tree. Ecol. Lett. 9, 569-574. doi: 10.1111/j.1461-0248.2006.00905.x

Bessler, H., Oelmann, Y., Roscher, C., Buchmann, N., Scherer-Lorenzen, M., Schulze, E.-D., et al. (2012). Nitrogen uptake by grassland communities: contribution of N2 fixation, facilitation, complementarity, and species dominance. Plant Soil 358, 301-322. doi: 10.1007/s11104-012-1181-z

Bever, J. D. (1994). Feeback between plants and their soil communities in an old field community. Ecology 75, 1965-1977. doi: 10.2307/1941601

Bever, J. D., Westover, K. M., and Antonovics, J. (1997). Incorporating the soil community into plant population dynamics: the utility of the feedback approach. J. Ecol. 85, 561-573. doi: 10.2307/2960528

Bezemer, T. M., Jing, J., Bakx-Schotman, J. M. T., and Bijleveld, E.-J. (2018). Plant competition alters the temporal dynamics of plant-soil feedbacks. J. Ecol. 106, 2287-2300. doi: 10.1111/1365-2745.12999

Brandt, A. J., Leahy, S. C., Zimmerman, N. M., and Burns, J. H. (2015). Plant trait expression responds to establishment timing. Oecologia 178, 525-536. doi: $10.1007 /$ s00442-014-3216-z

Burkey, T. V. (1994). Tropical tree species diversity: a test of the janzen-connell model. Oecologia 97, 533-540. doi: 10.1007/BF00325893

Callaway, R. M., Thelen, G. C., Barth, S., Ramsey, P. W., and Gannon, J. E. (2004). Soil fungi alter interactions between the invader centaurea maculosa and north American natives. Ecology 85, 1062-1071. doi: 10.1890/02-0775 analyses and made figures. SK guided data analysis. KB ran all final analyses and made all final figures. KB, JM, JAS, and JB coordinated writing, to which all authors contributed. Ideas were conceived of by all authors.

\section{ACKNOWLEDGMENTS}

We thank the organizers of this special feature and the University of Tennessee. Special thanks to individual authors of published studies who generously contributed requested data. We also thank the two reviewers who provided very beneficial feedback on this manuscript.

\section{SUPPLEMENTARY MATERIAL}

The Supplementary Material for this article can be found online at: https://www.frontiersin.org/articles/10.3389/fevo. 2020.00191/full\#supplementary-material

Callaway, R. M., and Walker, L. R. (1997). Competition and facilitation: a synthetic approach to interactions in plant communities. Ecology 78, 1958-1965. doi: 10. 1890/0012-965819970781958:CAFASA2.0.CO;2

Chen, H., Wang, R. Q., Ge, X. L., Zhang, J., Du, N., Wang, W., et al. (2012). Competition and soil fungi affect the physiological and growth traits of an alien and a native tree species. Photosynthetica 50, 77-85. doi: 10.1007/s11099-012-0013-y

Chesson, P. (2000). General theory of competitive coexistence in spatiallyvarying environments. Theor. Popul. Biol. 58, 211-237. doi: 10.1006/tpbi.2000. 1486

Chung, Y. A., and Rudgers, J. A. (2016). Plant-soil feedbacks promote negative frequency dependence in the coexistence of two aridland grasses. Proc. R. Soc. B Biol. Sci. 283:20160608. doi: 10.1098/rspb.2016.0608

Comita, L. S., Queenborough, S. A., Murphy, S. J., Eck, J. L., Xu, K., Krishnadas, M., et al. (2014). Testing predictions of the Janzen-Connell hypothesis: a meta-analysis of experimental evidence for distance- and density-dependent seed and seedling survival. J. Ecol. 102, 845-856. doi: 10.1111/1365-2745. 12232

Coykendall, K. E., and Houseman, G. R. (2014). Lespedeza cuneata invasion alters soils facilitating its own growth. Biol. Invasions 16, 1735-1742. doi: 10.1007/s10530-013-0623-8

Crawford, K. M., Bauer, J. T., Comita, L. S., Eppinga, M. B., Johnson, D. J., Mangan, S. A., et al. (2019). When and where plant-soil feedback may promote plant coexistence: a meta-analysis. Ecol. Lett. 22, 1274-1284. doi: 10.1111/ele. 13278

Dai, A. (2013). Increasing drought under global warming in observations and models. Nat. Clim. Change 3, 52-58. doi: 10.1038/nclimate1633

de la Peña, E., de Clercq, N., Bonte, D., Roiloa, S., Rodríguez-Echeverría, S., and Freitas, H. (2010). Plant-soil feedback as a mechanism of invasion by carpobrotus edulis. Biol. Invasions 12, 3637-3648. doi: 10.1007/s10530-010-9756-1

De Long, J. R., Heinen, R., Steinauer, K., Hannula, S. E., Huberty, M., Jongen, R., et al. (2019). Taking plant-soil feedbacks to the field in a temperate grassland. Basic Appl. Ecol. 40, 30-42. doi: 10.1016/j.baae.2019.08.001

Dooley, S. R., and Treseder, K. K. (2012). The effect of fire on microbial biomass: a meta-analysis of field studies. Biogeochemistry 109, 49-61. doi: 10.1007/s10533-011-9633-8

Ehrenfeld, J. G., Ravit, B., and Elgersma, K. (2005). Feedback in the plant-soil system. Annu. Rev. Environ. Resour. 30, 75-115. doi: 10.1146/annurev.energy.30.050504.144212

Erisman, J. W., Galloway, J. N., Seitzinger, S., Bleeker, A., Dise, N. B., Petrescu, A. R., et al. (2013). Consequences of human modification of 
the global nitrogen cycle. Philos. Trans. R. Soc. B Biol. Sci. 368:20130116. doi: 10.1098/rstb.2013.0116

Florianová, A., and Münzbergová, Z. (2018). The intensity of intraspecific plantsoil feedbacks in alien impatiens species depends on the environment. Perspect. Plant Ecol. Evol. Syst. 32, 56-64. doi: 10.1016/j.ppees.2018.04.004

Forero, L. E., Grenzer, J., Heinze, J., Schittko, C., and Kulmatiski, A. (2019). Greenhouse- and field-measured plant-soil feedbacks are not correlated. Front. Environ. Sci. 7:184. doi: 10.3389/fenvs.2019.00184

Fox, J., Friendly, M., and Weisberg, S. (2013). Hypothesis tests for multivariate linear models using the car package. $R$ J. 5, 39-52. doi: 10.32614/RJ-2013-004

Grime, J. P. (1977). Evidence for the existence of three primary strategies in plants and its relevance to ecological and evolutionary theory. Am. Nat. 111, 1169-1194. doi: 10.1086/283244

Hawkins, A. P., and Crawford, K. M. (2018). Interactions between plants and soil microbes may alter the relative importance of intraspecific and interspecific plant competition in a changing climate. AoB PLANTS 10:ply039. doi: 10.1093/aobpla/ply039

Heinze, J., and Joshi, J. (2018). Plant-soil feedback effects can be masked by aboveground herbivory under natural field conditions. Oecologia 186, 235-246. doi: 10.1007/s00442-017-3997-y

Heinze, J., Sitte, M., Schindhelm, A., Wright, J., and Joshi, J. (2016). Plantsoil feedbacks: a comparative study on the relative importance of soil feedbacks in the greenhouse versus the field. Oecologia 181, 559-569. doi: $10.1007 / \mathrm{s} 00442-016-3591-8$

Herms, D. A., and Mattson, W. J. (1992). The dilemma of plants: to grow or defend. Q. Rev. Biol. 67, 283-335. doi: 10.1086/417659

Hersh, M. H., Vilgalys, R., and Clark, J. S. (2012). Evaluating the impacts of multiple generalist fungal pathogens on temperate tree seedling survival. Ecology 93, 511-520. doi: 10.1890/11-0598.1

Hillebrand, H., and Kunze, C. (2020). Meta-analysis on pulse disturbances reveals differences in functional and compositional recovery across ecosystems. Ecol. Lett. 23, 575-585. doi: 10.1111/ele.13457

Johnson, D. J., Beaulieu, W. T., Bever, J. D., and Clay, K. (2012). Conspecific negative density dependence and forest diversity. Science 336, 904-907. doi: 10.1126/science.1220269

Kaisermann, A., Vries, F. T., de, Griffiths, R. I., and Bardgett, R. D. (2017). Legacy effects of drought on plant-soil feedbacks and plant-plant interactions. New Phytol. 215, 1413-1424. doi: 10.1111/nph.14661

Kannenberg, S. A., and Phillips, R. P. (2017). Soil microbial communities buffer physiological responses to drought stress in three hardwood species. Oecologia 183, 631-641. doi: 10.1007/s00442-016-3783-2

Kardol, P., Deyn, G. B. D., Laliberté, E., Mariotte, P., and Hawkes, C. V. (2013). Biotic plant-soil feedbacks across temporal scales. J. Ecol. 101, 309-315. doi: 10.1111/1365-2745.12046

Kivlin, S. N., Bedoya, R., and Hawkes, C. V. (2018). Heterogeneity in arbuscular mycorrhizal fungal communities may contribute to inconsistent plant-soil feedback in a neotropical forest. Plant Soil 432, 29-44. doi: $10.1007 / \mathrm{s} 11104-018-3777-4$

Kivlin, S. N., Emery, S. M., and Rudgers, J. A. (2013). Fungal symbionts alter plant responses to global change. Am. J. Bot. 100, 1445-1457. doi: $10.3732 / \mathrm{ajb} .1200558$

Klironomos, J. N. (2002). Feedback with soil biota contributes to plant rarity and invasiveness in communities. Nature 417, 67-70. doi: 10.1038/417067a

Kulmatiski, A., Beard, K. H., Stevens, J. R., and Cobbold, S. M. (2008). Plant-soil feedbacks: a meta-analytical review. Ecol. Lett. 11, 980-992. doi: 10.1111/j.1461-0248.2008.01209.x

Kulmatiski, A., and Kardol, P. (2008). "Getting plant-soil feedbacks out of the greenhouse: experimental and conceptual approaches," in Progress in Botany, eds. U. Lüttge, W. Beyschlag, and J. Murata (Berlin, Heidelberg: Springer), 449-472. doi: 10.1007/978-3-540-72954-9_18

Larios, L., and Suding, K. N. (2015). Competition and soil resource environment alter plant-soil feedbacks for native and exotic grasses. AoB PLANTS 7:plu077. doi: 10.1093/aobpla/plu077

Lau, J. A., and Lennon, J. T. (2012). Rapid responses of soil microorganisms improve plant fitness in novel environments. Proc. Natl. Acad. Sci.U.S.A. 109, 14058-14062. doi: 10.1073/pnas.1202319109

Lekberg, Y., Bever, J. D., Bunn, R. A., Callaway, R. M., Hart, M. M., Kivlin, S. N., et al. (2018). Relative importance of competition and plant-soil feedback, their synergy, context dependency and implications for coexistence. Ecol. Lett. 21, 1268-1281. doi: 10.1111/ele.13093

Long, J. R. D., Fry, E. L., Veen, G. F., and Kardol, P. (2019). Why are plant-soil feedbacks so unpredictable, and what to do about it? Funct. Ecol. 33, 118-128. doi: $10.1111 / 1365-2435.13232$

Lozano, Y. M., Hortal, S., Armas, C., and Pugnaire, F. I. (2019). Soil microorganisms and competitive ability of a tussock grass species in a dry ecosystem. J. Ecol. 107, 1215-1225. doi: 10.1111/1365-2745.13104

Mangan, S. A., Schnitzer, S. A., Herre, E. A., Mack, K. M. L., Valencia, M. C., Sanchez, E. I., et al. (2010). Negative plant-soil feedback predicts tree-species relative abundance in a tropical forest. Nature 466, 752-755. doi: 10.1038 /nature 09273

Maron, J. L., Smith, A. L., Ortega, Y. K., Pearson, D. E., and Callaway, R. M. (2016). Negative plant-soil feedbacks increase with plant abundance, and are unchanged by competition. Ecology 97, 2055-2063. doi: 10.1002/ec y.1431

Medina-Roldán, E., Paz-Ferreiro, J., and Bardgett, R. D. (2012). Grazing-induced effects on soil properties modify plant competitive interactions in seminatural mountain grasslands. Oecologia 170, 159-169. doi: 10.1007/s00442-012$2287-\mathrm{y}$

Mills, K. E., and Bever, J. D. (1998). Maintenance of diversity within plant communities: soil pathogens as agents of negative feedback. Ecology 79, 1595-1601. doi: 10.1890/0012-965819980791595:MODWPC2.0.CO;2

Nagendra, U. J., and Peterson, C. J. (2016). Plant-soil feedbacks differ in intact and tornado-damaged areas of the southern Appalachian mountains, USA. Plant Soil 402, 103-116. doi: 10.1007/s11104-015-2766-0

Pressler, Y., Moore, J. C., and Cotrufo, M. F. (2019). Belowground community responses to fire: meta-analysis reveals contrasting responses of soil microorganisms and mesofauna. Oikos 128, 309-327. doi: 10.1111/oik.05738

Putten, W. H., van der, Bardgett, R. D., Bever, J. D., Bezemer, T. M., Casper, B. B., Fukami, T., et al. (2013). Plant-soil feedbacks: the past, the present and future challenges. J. Ecol. 101, 265-276. doi: 10.1111/1365-2745.12054

Putten, W. H., van der, Bradford, M. A., Brinkman, E. P., Voorde, T. F. J., van de, and Veen, G. F. (2016). Where, when and how plant-soil feedback matters in a changing world. Funct. Ecol. 30, 1109-1121. doi: 10.1111/1365-2435. 12657

Qin, Y., Druzhinina, I. S., Pan, X., and Yuan, Z. (2016). Microbially mediated plant salt tolerance and microbiome-based solutions for saline agriculture. Biotechnol. Adv. 34, 1245-1259. doi: 10.1016/j.biotechadv.2016.08.005

Rau, B. M., Chambers, J. C., Blank, R. R., and Johnson, D. W. (2008). Prescribed fire, soil, and plants: burn effects and interactions in the central great basin. Rangel. Ecol. Manag. 61, 169-181. doi: 10.2111/07-037.1

Reich, P. B. (2014). The world-wide 'fast-slow' plant economics spectrum: a traits manifesto. J. Ecol. 102, 275-301. doi: 10.1111/1365-2745. 12211

Reinhart, K. O., Johnson, D., and Clay, K. (2012). Conspecific plant-soil feedbacks of temperate tree species in the southern appalachians, USA. PLoS ONE 7:e40680. doi: 10.1371/journal.pone.0040680

Revillini, D., Gehring, C. A., and Johnson, N. C. (2016). The role of locally adapted mycorrhizas and rhizobacteria in plant-soil feedback systems. Funct. Ecol. 30, 1086-1098. doi: 10.1111/1365-2435.12668

Reynolds, H. L., Packer, A., Bever, J. D., and Clay, K. (2003). Grassroots ecology: plant-microbe-soil interactions as drivers of plant community structure and dynamics. Ecology 84, 2281-2291. doi: 10.1890/02-0298

Rolhauser, A. G., Chaneton, E. J., and Batista, W. B. (2011). Influence of conspecific and heterospecific adults on riparian tree species establishment during encroachment of a humid palm savanna. Oecologia 167, 141-148. doi: 10.1007/s00442-011-1957-5

Rosado, B. H. P., and de Mattos, E. A. (2017). On the relative importance of CSR ecological strategies and integrative traits to explain species dominance at local scales. Funct. Ecol. 31, 1969-1974. doi: 10.1111/1365-2435.12894

Schafer, J. L., and Mack, M. C. (2010). Short-term effects of fire on soil and plant nutrients in palmetto flatwoods. Plant Soil 334, 433-447. doi: 10.1007/s11104-010-0394-2

Schittko, C., Runge, C., Strupp, M., Wolff, S., and Wurst, S. (2016). No evidence that plant-soil feedback effects of native and invasive plant species under glasshouse conditions are reflected in the field. J. Ecol. 104, 1243-1249. doi: $10.1111 / 1365-2745.12603$ 
Senior, J. K., O’Reilly-Wapstra, J. M., Schweitzer, J. A., Bailey, J. K., and Potts, B. M. (2018). Forest fire may disrupt plant-microbial feedbacks. Plant Ecol. 219, 497-504. doi: 10.1007/s11258-018-0811-9

Shivega, W. G., and Aldrich-Wolfe, L. (2017). Native plants fare better against an introduced competitor with native microbes and lower nitrogen availability. AoB Plants 9:plx004. doi: 10.1093/aobpla/plx004

Smith-Ramesh, L. M., and Reynolds, H. L. (2017). The next frontier of plantsoil feedback research: unraveling context dependence across biotic and abiotic gradients. J. Veg. Sci. 28, 484-494. doi: 10.1111/jvs.12519

Spear, E. R., Coley, P. D., and Kursar, T. A. (2015). Do pathogens limit the distributions of tropical trees across a rainfall gradient? J. Ecol. 103, 165-174. doi: 10.1111/1365-2745.12339

Tilman, D. (1982). Resource Competition and Community Structure. Princeton, NJ: Princeton University Press. doi: 10.1515/9780691209654

Tilman, D. (1990). Constraints and tradeoffs: toward a predictive theory of competition and succession. Oikos 58, 3-15. doi: 10.2307/3565355

Treseder, K. K., and Allen, M. F. (2002). Direct nitrogen and phosphorus limitation of arbuscular mycorrhizal fungi: a model and field test. New Phytol. 155, 507-515. doi: 10.1046/j.1469-8137.2002.00470.x

Valliere, J. M., and Allen, E. B. (2016). Interactive effects of nitrogen deposition and drought-stress on plant-soil feedbacks of artemisia californica seedlings. Plant Soil 403, 277-290. doi: 10.1007/s11104-015-2776-y

Van Der Heijden, M. G. A., Bardgett, R. D., and Van Straalen, N. M. (2018). The unseen majority: soil microbes as drivers of plant diversity and productivity in terrestrial ecosystems. Ecol. Lett. 11, 296-310. doi: 10.1111/j.1461-0248.2007.01139.x

Viechtbauer, W. (2010). Conducting meta-analyses in $\mathrm{R}$ with the metafor package. J. Stat. Softw. 36, 1-48. doi: 10.18637/jss.v036.i03

Vílchez, J. I., García-Fontana, C., Román-Naranjo, D., González-López, J., and Manzanera, M. (2016). Plant drought tolerance enhancement by trehalose production of desiccation-tolerant microorganisms. Front. Microbiol. 7:1577. doi: $10.3389 /$ fmicb.2016.01577

Wallenda, T., and Kottke, I. (1998). Nitrogen deposition and ectomycorrhizas. N. Phytol. 139, 169-187. doi: 10.1046/j.1469-8137.1998.00176.x

Wardle, D. A., Bardgett, R. D., Klironomos, J. N., Setälä, H., Putten, W. H., van der Wall, D. H. (2004). Ecological linkages between aboveground and belowground biota. Science 304, 1629-1633. doi: 10.1126/science.1094875

Whalen, E. D., Smith, R. G., and Grandy, A. S., and Frey, S. D. (2018). Manganese limitation as a mechanism for reduced decomposition in soils under atmospheric nitrogen deposition. Soil Biol. Biochem. 127, 252-263. doi: 10.1016/j.soilbio.2018.09.025

Whitman, T., Whitman, E., Woolet, J., Flannigan, M. D., Thompson, D. K., and Parisien, M.-A. (2019). Soil bacterial and fungal response to wildfires in the Canadian boreal forest across a burn severity gradient. Soil Biol. Biochem. 138:107571. doi: 10.1016/j.soilbio.2019.107571

Wooliver, R. C., Marion, Z. H., Peterson, C. R., Potts, B. M., Senior, J. K., Bailey, J. K., et al. (2017). Phylogeny is a powerful tool for predicting plant biomass responses to nitrogen enrichment. Ecology 98, 2120-2132. doi: 10.1002/ecy.1896

Xue, W., Bezemer, T. M., and Berendse, F. (2018). Density-dependency and plantsoil feedback: former plant abundance influences competitive interactions between two grassland plant species through plant-soil feedbacks. Plant Soil 428, 441-452. doi: 10.1007/s11104-018-3690-x

Yu, L., Song, M., Lei, Y., Duan, B., Berninger, F., Korpelainen, H., et al. (2017). Effects of phosphorus availability on later stages of primary succession in gongga mountain glacier retreat area. Environ. Exp. Bot. 141, 103-112. doi: 10.1016/j.envexpbot.2017.07.010

Zhang, Q., Sun, Q., Koide, R. T., Peng, Z., Zhou, J., Gu, X., et al. (2014). Arbuscular mycorrhizal fungal mediation of plant-plant interactions in a marshland plant community. Sci. World J. 2014:923610. doi: 10.1155/2014/923610

Zhao, N., Gao, S., Ren, H., Yang, X., Sun, Z., Wang, J., et al. (2018). Competition alters plant-soil feedbacks of two species in the inner mongolia steppe, China. Plant Soil 429, 425-436. doi: 10.1007/s11104-018-3703-9

Zuppinger-Dingley, D., Flynn, D. F. B., Deyn, G. B. D., Petermann, J. S., and Schmid, B. (2016). Plant selection and soil legacy enhance long-term biodiversity effects. Ecology 97, 918-928. doi: 10.1890/15-0599.1

Conflict of Interest: The authors declare that the research was conducted in the absence of any commercial or financial relationships that could be construed as a potential conflict of interest.

Copyright (C) 2020 Beals, Moore, Kivlin, Bayliss, Lumibao, Moorhead, Patel, Summers, Ware, Bailey and Schweitzer. This is an open-access article distributed under the terms of the Creative Commons Attribution License (CC BY). The use, distribution or reproduction in other forums is permitted, provided the original author(s) and the copyright owner(s) are credited and that the original publication in this journal is cited, in accordance with accepted academic practice. No use, distribution or reproduction is permitted which does not comply with these terms. 